\title{
A Telephone Helpline Assessment of Psychosocial Needs of Adults with Cancer Post Institute of Medicine (IOM) Recommendations
}

\author{
Paula Klemm ${ }^{1 *}$, Veronica F. Rempusheski ${ }^{1}$, Claudine Jurkovitz ${ }^{2}$, Paul Kolm², Wei Zhang² \\ ${ }^{1}$ School of Nursing, University of Delaware, Newark, USA \\ ${ }^{2}$ Christiana Care Center for Outcomes Research (CCOR) Value Institute, Christiana Care Health System, \\ Newark, USA \\ Email: ${ }^{*}$ klemmpa@udel.edu
}

Received 1 September 2014; revised 1 October 2014; accepted 19 October 2014

Copyright (C) 2014 by authors and Scientific Research Publishing Inc.

This work is licensed under the Creative Commons Attribution International License (CC BY). http://creativecommons.org/licenses/by/4.0/

(c) (i) Dpen Access

\begin{abstract}
Objective: To explore whether the 2007 IOM recommendations had an impact on the reasons for calls to a cancer telephone helpline and determine the major reasons for calls at two different time periods after the 2007 recommendations. Methods: Caller data with identifiers removed were extracted from a cancer helpline database. Baseline data included calls made to the helpline between April 2, 2008 and September 2, 2009 (Period 1). Then, a second data set was built from data collected between September 3, 2009 and May 2, 2011 (Period 2). Results: The major reasons for calls to the cancer telephone helpline during the two different time periods were the same: financial assistance, helpline services information, coping assistance, support groups, and questions related to treatment. Four of the top five reasons were non-treatment related (i.e., financial issues, helpline services information, coping, and support). Conclusions: The nature of calls to the helpline suggests that the financial and psychosocial needs of people with cancer are not being addressed by healthcare providers. Practice implications: The new "normal" for cancer care includes decisions about complex care coupled with new regulatory and financial constraints. This underscores the importance of focused planning of cancer care across multiple care settings in order to ensure continuity of care for the whole person.
\end{abstract}

\section{Keywords}

Cancer Patients, Cancer Helpline, Psychosocial Needs, 2007 IOM Recommendations

\footnotetext{
${ }^{*}$ Corresponding author.
}

How to cite this paper: Klemm, P., Rempusheski, V.F., Jurkovitz, C., Kolm, P. and Zhang, W. (2014) A Telephone Helpline Assessment of Psychosocial Needs of Adults with Cancer Post Institute of Medicine (IOM) Recommendations. Open Journal of Nursing, 4, 797-807. http://dx.doi.org/10.4236/ojn.2014.411085 


\section{Introduction}

Cancer survivors in the United States (US) number over 13 million in 2014, with more than 71\% of these individuals over the age of 60 years [1] [2]. Cancer risk increases with age, so the number of survivors is expected to increase significantly over the next decade as the US population ages. People with cancer and their family caregivers want information about their disease, but these needs vary depending of the type of cancer, extent of disease, personal situation, and age [3] [4]. Although education about cancer diagnosis and treatment is usually provided to people with cancer and family caregivers by their healthcare providers, a discussion about social, lifestyle, and financial concerns is often lacking or inadequate [5]-[7]. Regardless of age or lifestyle all people with cancer and their family caregivers want accurate and timely information related to their disease to help inform their healthcare decision-making. Those who receive and understand information about their cancer are more involved in making decisions about their treatment and report greater satisfaction with their treatment choices [4] [8].

In 2007, the Institute of Medicine (IOM) put forth recommendations to care for the whole person with cancer [9]. This meant not only addressing treatment-related issues, but also providing interventions to meet psychosocial needs [9]. More recently, the National Comprehensive Cancer Network (NCCN) (an alliance of leading cancer centers) published clinical practice guidelines, which included specific recommendations for providing psychosocial care for people with cancer in clinical practice [10]. In addition, the Commission on Cancer (CoC) (a consortium of professional organizations dedicated to improving survival and quality of life for people with cancer) issued cancer program standards in 2012. These standards focused on patient-centered care, meeting psychosocial needs, and screening for psychosocial distress [11].

In spite of the recommendations from the IOM and practice guidelines provided by the NCCN and CoC, the provision of psychosocial needs is not typically integrated into clinical practice. According to the IOM, "attention to patients' psychosocial health needs is the exception rather than the rule in cancer care” [9] (para 3). Therefore, people with cancer may live longer due to better treatment, but without the benefit of having their psychosocial health needs adequately addressed.

\subsection{Cancer Patients' Informational Needs}

Health-related information may be provided to people with cancer in a variety of ways including face-to-face discussions with a health care provider, health promotion literature, and informational brochures. However, people with cancer frequently seek information from sources other than their healthcare providers [4] [12]. Many access the internet for cancer related information to learn about their disease or to help them make treatment related decisions [6] [8] [13]-[15]. Certain subgroups of people with cancer, primarily those who are older, have lower levels of education, or are unemployed may prefer other sources to obtain the information they need (e.g., support groups, cancer information services) [4] [16]-[20]. Older adults with cancer can have different information and support needs than those who are younger and are more likely to have difficulty processing and recalling information. In addition, they may be more hesitant to ask questions or seek additional information from their healthcare provider. One source indicated that older adults with cancer, as a group, had the poorest health literacy and were subjected to the least effective communication by healthcare professionals [16]. Older adults with cancer frequently experience co-morbid conditions (e.g., physical, cognitive, sensory impairments) that can negatively influence whether and to what extent they receive the information they need.

\subsection{Cancer Helplines}

Telephone-based cancer helplines have provided critical cancer-related information to people with cancer and their caregivers for more than three decades [18]-[27]. They are a reliable source of information for people with cancer and their caregivers, especially those who do not have internet access or who prefer talking directly to a cancer resource professional [18] [22] [24]. Similar to the internet, telephone helplines are not constrained by geographic location or transportation issues and grant a certain degree of anonymity to the caller. Telephone helplines may be an alternative for people with cancer and their caregivers when a face-to-face meeting with a healthcare provider is not possible (e.g., distance, mobility problems, lack of transportation). Telephone helplines may not be appropriate for those who have hearing impairments and/or those who do not have access to a telephone. 


\subsection{Purpose}

Given the emphasis on meeting psychosocial needs put forth by the IOM (and supported by the NCCN and $\mathrm{CoC}$ ), the evidence of these needs not being met, and the paucity of data about incorporation of recommendations in practice, we wondered whether the 2007 IOM recommendations had any impact over time on the reasons for calling a cancer telephone helpline [5]-[7]. We examined the major reasons that individuals called a cancer telephone helpline at two different time periods after the 2007 IOM recommendations were published [9].

\section{Methods}

Approval for this study was granted by the Human Subjects Committees at the University of Delaware and the Christiana Care Health System. The research team was composed of investigators from the University of Delaware, School of Nursing (UDSON), a Steering Committee composed of community stakeholders, staff from the Cancer Care Connection cancer helpline, and biostatisticians from the Christiana Care Center for Outcomes Research (CCOR).

\subsection{Data Source/Instrument}

This report is a secondary analysis of data from a larger study which focused on outreach to older adults with cancer in Delaware. Data include all of the caller records in a non-profit telephone helpline database between April 2, 2008 and May 2, 2011. The first timeframe for data collection took place between April 2, 2008 and September 2, 2009. The second timeframe for data collection took place between September 3, 2009 and May 2, 2011. We assumed that it would take at least six months (i.e. April 2008) for the IOM report to circulate and begin to be implemented into practice.

The telephone helpline in this study is a non-profit service organization located in Delaware which assists people to make informed decisions and take action on their own behalf through professional coaching, personalized information, and resource connections. Master's prepared social workers, trained as Cancer Resource Coaches $\odot$ (CRCs), answer all in-coming telephone calls from people with cancer and/or their family caregivers. The goals of each interaction include a full psychosocial assessment, direct intervention to resolve the presenting problem, exploration of concurrent problems, and planning the next steps to address each issue. Once a call is made to the helpline, the CRC enters the data into a secure electronic database to track demographic, disease related information such as diagnosis, type of cancer, treatment issues, and the presenting problem including social, lifestyle, and financial concerns as well as documentation of follow-up and questions about satisfaction with helpline services.

The helpline support services are provided free of charge. Callers to the helpline are people with cancer (calling for information for themselves), caregivers, or other individuals seeking information for a person with cancer, including family members, friends, healthcare providers, co-workers and community agents.

\subsection{Data Analysis}

Caller data, with all identifiers removed were extracted from the helpline data base to describe the characteristics of callers in the two time periods. Baseline data included calls made to the helpline between April 2, 2008 and September 2, 2009 (Period 1). Then, a second data set was built from data collected between September 3, 2009 and May 2, 2011 (Period 2). Characteristics of people with cancer including relationship of caller to the person with cancer, gender, age, type of cancer and the reasons for the calls were tabulated for both Period 1 and Period 2 .

\section{Results}

During Period 1, 650 callers telephoned the helpline for cancer related information. Callers included people with cancer calling for information for themselves, family members calling for the people with cancer, and others (e.g., neighbor; co-worker). Fifty-eight percent of callers indicated that they lived in Delaware and the rest were from 27 other states and one Canadian province. During Period 2, 725 callers from Delaware and from 36 states across the US contacted the helpline. Forty-five percent indicated that they lived in Delaware $(\mathrm{n}=325)$.

For people with cancer during Period 1, data indicated that $45.2 \%$ were less than 65 years of age; $15.7 \%$ over 
the age of 65, and 39.2\% had unknown age (Table 1). By comparison, during Period 2, 52.0\% of the people with cancer were younger than 65 years, $21.8 \%$ were 65 or older, and $26.2 \%$ had missing age information. The majority of people with cancer were men in both Period 1 and Period 2 (52.5\% and 56.6\%) (Table 1). However, the gender of those who called was primarily female in both Periods (79.2\% vs.74.3\%) (Table 2).

Most of the people with cancer were Caucasian, but race information was missing in 35.4\% of patients in Period 1 and 29.8\% in Period 2 (Table 1). The four most common cancers about which callers requested information during Period 1 were breast, lung, colorectal, and prostate cancer. Prostate fell to $5^{\text {th }}$ (behind lymphoma) in Period 2, a decrease of $48 \%$. Other malignancies about which callers requested information included leukemia and cancer of the ovary, pancreas, stomach, liver, thyroid and others.

A total of $41.7 \%$ of people with cancer had insurance in Period 1 and $49.0 \%$ had insurance in Period 2, while 8.6\% did not have insurance in either Period. Information on insurance status was unknown in $49.7 \%$ during Period 1 and $42.5 \%$ in Period 2 (Table 1); When insurance status was stratified by age, the data indicated that more people $\geq 65$ reported having insurance in both Period 1 (69.6\% versus 55.3\%) and Period 2 (72.8\% versus $58.1 \%)$.

The five most frequent reasons that callers telephoned the helpline for information in both Period1 and Period 2 were: financial assistance, helpline services information, coping assistance, support groups, and questions

Table 1. Characteristics of people with cancer: Period 1 and Period 2.

\begin{tabular}{|c|c|c|}
\hline & First data period $n=650$ & Second data period $n=725$ \\
\hline \multicolumn{3}{|l|}{ Age } \\
\hline Youth: 17 and under; n (\%) & $4(0.6)$ & $6(0.8)$ \\
\hline Young Adult: 18 - 30; n (\%) & $17(2.6)$ & $23(3.2)$ \\
\hline Adult: 31 - 45; n (\%) & $65(10.0)$ & $77(10.6)$ \\
\hline Mature Adult: 46 - 64; n (\%) & 207 (31.9) & $271(37.4)$ \\
\hline Senior: 65 and over; n (\%) & $102(15.7)$ & $158(21.8)$ \\
\hline Unknown; n (\%) & $255(39.2)$ & $190(26.2)$ \\
\hline \multicolumn{3}{|l|}{ Gender } \\
\hline Female, n (\%) & $167(25.7)$ & 202 (27.9) \\
\hline Male, n (\%) & $341(52.5)$ & $410(56.6)$ \\
\hline Unknown, n (\%) & $142(21.9)$ & $113(15.6)$ \\
\hline \multicolumn{3}{|l|}{ Race } \\
\hline White, n (\%) & $301(46.3)$ & $372(51.3)$ \\
\hline African American, n (\%) & $92(14.2)$ & $107(14.8)$ \\
\hline Hispanic, n (\%) & $12(1.9)$ & $7(1.0)$ \\
\hline Asian, n (\%) & $11(1.7)$ & $7(1.0)$ \\
\hline Native American, n (\%) & 0 & $1(0.1)$ \\
\hline Other, n (\%) & $4(0.6)$ & $15(2.1)$ \\
\hline Unknown, n (\%) & $230(35.4)$ & $216(29.8)$ \\
\hline \multicolumn{3}{|l|}{ Insurance } \\
\hline Yes, n (\%) & $271(41.7)$ & $355(49.0)$ \\
\hline No, n (\%) & $56(8.6)$ & $62(8.6)$ \\
\hline Unknown, n (\%) & $323(49.7)$ & $308(42.5)$ \\
\hline
\end{tabular}


Table 2. Characteristics of all callers (people with cancer and caregivers) to the helpline: Period 1 and Period 2.

\begin{tabular}{|c|c|c|}
\hline & Period 1, n = 650 & Period 2, $n=725$ \\
\hline \multicolumn{3}{|l|}{ Age } \\
\hline Youth: 17 and under; n (\%) & $1(0.2)$ & $0(0.0)$ \\
\hline Young Adult: 18 - 30; n (\%) & $44(6.8)$ & $30(4.1)$ \\
\hline Adult: 31 - 45; n (\%) & $118(18.2)$ & $129(17.8)$ \\
\hline Mature Adult: 46 - 64; n (\%) & $248(38.2)$ & $322(44.4)$ \\
\hline Senior: 65 and over; n (\%) & $86(13.2)$ & $122(16.8)$ \\
\hline Unknown; n (\%) & $153(23.5)$ & $122(16.8)$ \\
\hline \multicolumn{3}{|l|}{ Gender } \\
\hline Female, n (\%) & $515(79.2)$ & 539 (74.3) \\
\hline Male, n (\%) & $121(18.6)$ & 144 (19.9) \\
\hline Unknown, n (\%) & $14(2.2)$ & $42(5.8)$ \\
\hline \multicolumn{3}{|l|}{ Race } \\
\hline White, n (\%) & $140(21.5)$ & 359 (49.5) \\
\hline African American, n (\%) & $49(7.5)$ & $105(14.5)$ \\
\hline Hispanic, n (\%) & $3(0.5)$ & $4(0.6)$ \\
\hline Asian, n (\%) & $4(0.6)$ & $6(0.8)$ \\
\hline Native American, n (\%) & 0 & $1(0.1)$ \\
\hline Other, n (\%) & 0 & $12(1.7)$ \\
\hline Unknown, n (\%) & 454 (69.9) & 238 (32.8) \\
\hline
\end{tabular}

related to treatment (Figure 1). These categories were further evaluated by age of person with cancer ( $<65$ vs. $\geq 65$ ). The most frequent call category in both Periods for those under age 65 was "financial assistance" (24.6\% Period 1; 27.6\% Period 2). In the $\geq 65$ age group, the most frequent call category in Period 1 was "financial assistance” (18.6\%), but in Period 2 it was "helpline services information” (22.8\%), followed by "financial assistance" (19.6\%) (Table 3).

\section{Discussion}

Four of the top five reasons that people called the helpline were non-treatment related (financial issues, helpline services information, coping assistance, and support groups) and these did not change between Period 1 and Period 2. The top three categories (financial assistance, helpline services information, and coping assistance) accounted for $54.6 \%$ of calls in people with cancer younger than 65 in Period 2 versus $44.0 \%$ in Period 1 and $55.7 \%$ of calls in those $\geq 65$ in Period 2 versus $37.2 \%$ in Period 1 . The reason for the increase in calls during Period 2 for "helpline services information" in those $\geq 65$ may be related to the focus on outreach to older adults with cancer as part of the larger study. The findings about the ongoing need for financial assistance, help with coping issues, and a need for additional information reflect those in other research reports published after the IOM report in 2007 and suggest that the IOM recommendations have not been fully implemented into cancer care [28][35].

When call categories were separated by the age of the person with cancer (i.e., patient) ( $<65$ vs. $\geq 65$ ) the percent of those seeking information about financial assistance was lower in the $\geq 65$ group (Table 3 ). This difference might be due in part to Medicare coverage that helps offset costs for those 65 years and older. One group of researchers utilized cancer registry data and Medicare claims to estimate the net cost of care for over 11 million older adults (>65 years) with cancer as compared to controls who did not have cancer [36]. The highest costs 


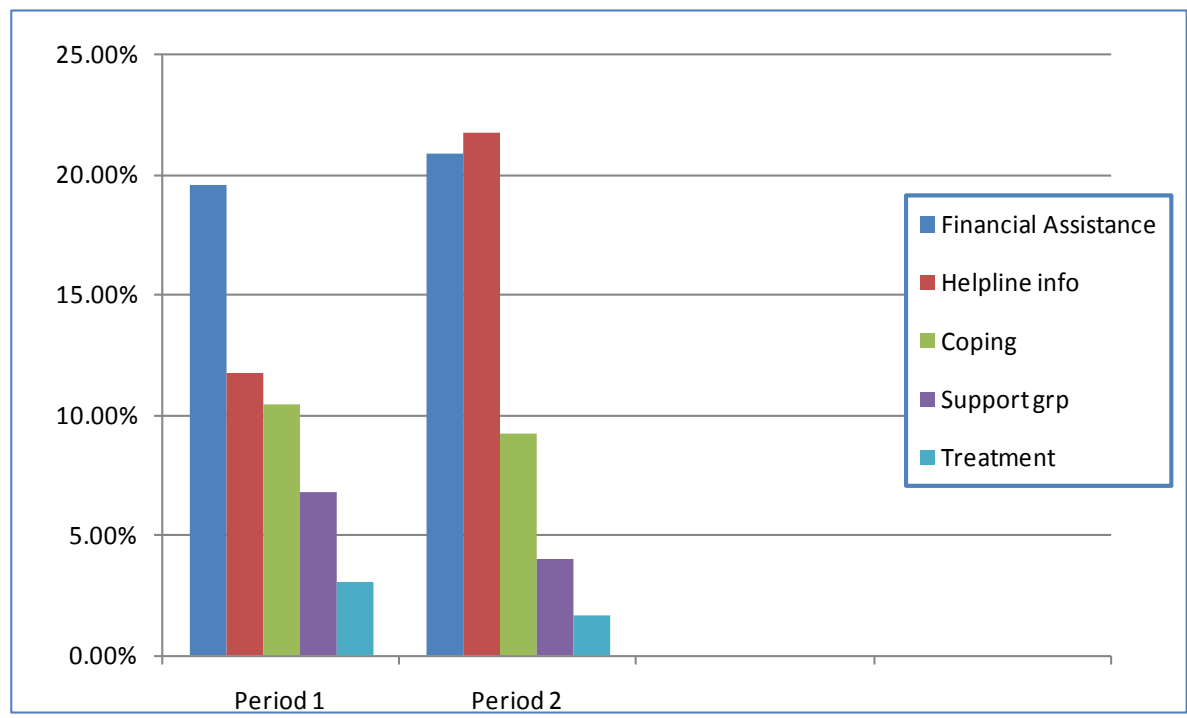

Figure 1. Five most frequent call categories: Period 1 and Period 2.

Table 3. Call description by the age of the patient: $<65$ and $\geq 65$ (most frequent call categories): Period 1 and Period 2.

\begin{tabular}{|c|c|c|c|c|}
\hline & All & Patient age $<65$ & Patient age $\geq 65$ & Unknown \\
\hline Period 1 & $\mathrm{n}=650$ & $\mathrm{n}=293(45.1)$ & $\mathrm{n}=102(15.7)$ & $\mathrm{n}=255(39.2)$ \\
\hline Financial Assistance; n (\%) & $127(19.5)$ & $72(24.6)$ & $19(18.6)$ & $36(14.1)$ \\
\hline Helpline information; $\mathrm{n}(\%)$ & $76(11.7)$ & $22(7.5)$ & $3(2.9)$ & $51(20.0)$ \\
\hline Coping assistance; n (\%) & $68(10.5)$ & 35 (11.9) & $16(15.7)$ & $17(6.7)$ \\
\hline Support groups; n (\%) & $44(6.8)$ & $22(7.5)$ & $4(3.9)$ & $18(7.1)$ \\
\hline Treatment; n (\%) & $20(3.1)$ & $7(2.4)$ & $6(5.9)$ & $7(2.8)$ \\
\hline Other, n (\%) & $274(42.2)$ & $128(43.7)$ & $50(49.0)$ & $96(37.7)$ \\
\hline Unknown, n (\%) & $41(6.3)$ & $7(2.4)$ & $4(3.9)$ & $30(11.8)$ \\
\hline Period 2 & $\mathrm{~N}=725$ & $\mathrm{~N}=377(52.0)$ & $\mathrm{N}=158(21.8)$ & $\mathrm{N}=190(38.4)$ \\
\hline Financial Assistance; n (\%) & $151(20.8)$ & $104(27.6)$ & $31(19.6)$ & $16(8.4)$ \\
\hline Helpline information; n (\%) & $157(21.7)$ & $65(17.2)$ & $36(22.8)$ & $56(29.5)$ \\
\hline Coping assistance; n (\%) & $67(9.2)$ & $37(9.8)$ & $21(13.3)$ & $9(4.7)$ \\
\hline Support groups; n (\%) & $29(4.0)$ & $16(4.2)$ & $10(6.3)$ & $3(1.6)$ \\
\hline Treatment; n (\%) & $12(1.7)$ & $8(2.1)$ & $3(1.9)$ & $1(0.5)$ \\
\hline Other, n (\%) & $253(34.9)$ & $143(37.9)$ & $52(32.9)$ & $58(30.5)$ \\
\hline Unknown, n (\%) & $56(7.7)$ & $4(1.1)$ & $5(3.2)$ & $47(24.7)$ \\
\hline
\end{tabular}

were associated with the first year of treatment and the year before death. The authors noted that the costs associated with cancer care for younger people with cancer would most likely be greater because younger people are more likely to choose more aggressive treatment options and adjuvant care. The helpline database used for data collection in this study included questions about the type of cancer and treatment stage for which the callers sought information. However, this information was difficult to obtain when the caller was not the person with cancer, but rather a family member, friend, or co-worker. Therefore, it was often not possible to match callers seeking financial assistance with stage of disease and age for this study. 
Mathews and Park suggested that people with cancer in financial need were not adequately screened by healthcare providers [35]. They cited a lack of a standardized approach to assessing the financial needs of people with cancer and reluctance of them to disclose financial concerns as barriers in indentifying patients with financial need. In some cases, the person's spouse or other family members are responsible for managing finances, so people with cancer may not be aware of any impeding financial issues. Regardless of age, the issue of financial burden in people with cancer will remain a problem and is expected to increase as a result of improved survival attributed to better screening, detection, and treatment [29] [34].

The IOM recommendations for providing financial advice/assistance to people with cancer included offering financial planning or counseling to people with cancer and their family caregivers. This might include basic information about the management of day-to-day activities such as bill paying. Another recommendation was for healthcare providers to ensure that people with cancer and caregivers receive insurance (e.g., health, disability) counseling as needed. Some people with cancer, including veterans, are unaware of their eligibility for certain benefits (e.g., Supplemental Security Income, Social Security Disability Income, veteran's benefits) and need advice on how to apply for them. Finally, the IOM recommended that supplemental financial grants could be available to people with cancer and caregivers [9]. Other interventions from the IOM, which can help decrease the financial impact of cancer on people and their caregivers are the provision of help with activities of daily living and information about legal services that are available to them (i.e., Americans with Disabilities Act; Family and Medical Leave Act) [9]. The ongoing calls to the helpline throughout Period 1 and Period 2 for financial help, suggests that healthcare providers, discharge planners, and insurers have work to do in this area.

In the current study $10.5 \%$ of callers in Period 1 and $9.2 \%$ of callers in Period 2 contacted the helpline to request information on coping strategies. In addition, 6.8\% in Period 1 and $4 \%$ in Period 2 requested information about support groups, and less than $4 \%$ in both Periods asked for information about treatment. One group of researchers, reporting on an oncology center hotline run by a university hospital, indicated that $27 \%$ of patients and 32\% of next-of-kin telephoned for information related to psychosocial issues [22]. The hotline was specifically designed to provide counseling on psychosocial issues and general information about cancer, which may account for the higher percent of calls related to psychosocial issues. An early report, published in 1983, noted that people with cancer and others who called a telephone helpline called most often for a referral to a support group, while requests for help to cope with treatment and its' side effects ranked $9^{\text {th }}$ [24]. Marcus and colleagues reported on a telephone counseling service at a medical center in the western US [23]. The Cancer Information and Counseling Line (CICL), staffed by Master's level trained counselors, was designed to offer information and brief counseling to people with cancer and significant others. The researchers indicated that callers most often contacted the CICL for information related to their disease and treatment. Requests for psychosocial support that included support resources and emotional response accounted for only $10.4 \%$ of calls. It appears from the literature that telephone helplines that focused on psychosocial issues received more calls related to these concerns and those that are aligned with oncology treatment centers received more calls about treatment.

The reasons for the higher percentage of callers who requested financial help and the relatively low percentage who asked for information on coping or support in the current study are unclear. In 2005, the IOM recommended the use of survivorship care plans (SCPs) for cancer survivors [37] [38]. One of the IOM recommendations was that healthcare professionals provide cancer survivors with information on the potential financial consequences of cancer and refer them to the appropriate resources. Perhaps people with cancer are being referred to the helpline by their healthcare providers as part of the IOM recommendation, although this is conjecture. According to one source, SCPs are not frequently utilized in National Cancer Institute (NCI)-designated cancer centers and there is only one such center in Delaware [37].

The primary goal of the helpline in this study was to connect callers with the resources they needed with regard to cancer care. One reason that callers may be less inclined to call the helpline for information on cancer treatment is that the helpline is not associated with a medical facility and the CRC's are social workers and not nurses or physicians. That being the case, people with cancer and their caregivers may contact the hospital, oncology center, or the physician's office for information on treatment, before turning to the helpline for that information. Given the current rate of unemployment, increased costs of care, and the number of uninsured or underinsured people in the US, it should not be surprising that financial concerns are a major reason that calls are made to the helpline.

Data from Period 1 and Period 2 indicated that women were more likely to be the callers, while men were more likely to be the persons with cancer for whom the call was made. These findings are consistent with those 
of others. Calls made to a telephone hotline in Northern Ireland for people who were receiving chemotherapy were the focus of a 2011 report [21]. Over 7400 calls were made to the chemotherapy telephone helpline (CTH) at a regional cancer and almost $69 \%$ were initiated by women. Of the people with cancer who called the CTH helpline, $44.2 \%$ were men and $54.3 \%$ were women. An early report by Carlsson and colleagues reviewed the use of a telephone helpline designed to offer information about cancer to people with cancer, family, and the public at a large medical center [22]. During one three-year period, 735 calls were made to the helpline. Seventy-seven percent of the callers were women. Other reports also indicated that women made up the majority of callers to a cancer helpline [18] [23].

The number of Latinos who called the helpline for cancer related information during both Period 1 and Period 2 was small. There are several factors that may account for this. Although the numbers of Latinos/Hispanics in Delaware has more than doubled since 2000, they only account for $8.4 \%$ of the state's population. This is less than half the percentage of the rest of the US (18.7\%) [39] [40]. The cancer incidence and mortality rates for Hispanics are lower than those of Non-Hispanic whites, which may help account for the fewer calls from this group [41]. Language may have been a barrier as well. None of the CRC's at the helpline was bilingual. Therefore, the CRC's could only offer help to those Latino/Hispanic callers who could speak and understand English. A 2009 report described trends in telephone and live-help use among Hispanic and Non-Hispanic users of the National Cancer Institute's cancer information service [42]. Forty-four percent of Hispanics who sought information on cancer prevention wanted it in Spanish. In addition, 37\% of Hispanics were exclusively Spanishspeaking. In order to provide the most effective cancer-related information to Latino/Hispanic callers via telephone helplines, it is imperative to have Spanish-speaking operators who are sensitive to the cultural and social environments of these callers. Data analysis indicated that the percent of African American (AA) callers increased from Period 1 to Period 2. Even though the percent of AA callers nearly doubled in Period 2, it did not reflect the overall percent of AA's in the state, which is $29.1 \%$. Outreach, designed to increase awareness of the cancer helpline to AA's may help increase the use of the cancer helpline in this group.

The research team noted a high percentage of missing data (i.e., unknown) both Period 1 and Period 2. This was due, in part, to the nature of the calls made to the helpline. Some callers left voice mail messages if the CRC lines were busy. CRC's returned each call, but could not reconnect with all callers. Other callers asked the CRC for specific information (e.g., a phone number or a webpage) and did not want to provide demographic or insurance information, while others preferred to remain anonymous.

Jefford and Colleagues described a cancer helpline offered by a large medical center in Australia [18]. A major limitation of the data analysis noted by the researchers was the nature of the dataset which they used. It was designed to guide the telephone interviews from the callers and some data were not available due to the confidential and anonymous nature of the calls. This problem also plagued the CRC's at the helpline who provided information to callers. Due to the nature of the communication (telephone) and the variety of reasons for which callers contacted the helpline, it was not possible to obtain complete information on every caller.

\section{Conclusion}

The IOM has recommended care for the whole person with cancer [9]. In addition, the NCCN and CoC emphasized the need for psychosocial care for persons with cancer [10] [11]. Cancer helplines are utilized by people with cancer and their caregivers as a reliable source of information. The major reasons that individuals called a cancer telephone helpline during two different time periods (April 2, 2008-September 2, 2009 and September 3, 2009-May 2, 2011) after the 2007 IOM recommendation remained constant [9]. The consistency of calls to the helpline throughout Period 1 and Period 2 for financial help, suggests that the financial needs of people with cancer are not being addressed by healthcare providers. Other major reasons for calls to the helpline were related to coping issues and to learn more about what the helpline had to offer. In addition, minority populations were underrepresented to calls to the helpline.

\section{Implications for Practice}

A diagnosis of cancer places increased responsibility on people with cancer and family caregivers and emphasizes the importance of providing a coordinated approach to cancer care by healthcare providers. The new "normal" for cancer care includes decisions about complex care coupled with new regulatory and financial constraints. This underscores the importance of focused planning of cancer care across multiple care settings to ensure 
continuity of care. In addition to treatment-related information, a discussion of the financial implications of cancer care, potential for significant out-of-pocket costs, and potential work time lost should take place between the healthcare providers and the patient at diagnosis and periodically during treatment. An assessment of coping skills and support needs during treatment should be undertaken as part of routine care and follow-up for people with cancer. Clinical practice guidelines are available to guide a comprehensive approach to cancer care. However, healthcare providers must demonstrate a commitment to implementing these guidelines to ensure care for the whole person with cancer across care settings. The Agency for Healthcare Research and Quality (AHRQ) recommended several ways to disseminate evidence to inform healthcare. These include communicating evidence in more than one venue and disseminating information in multiple formats [43]. Outreach to minority populations and the use of bilingual staff could help increase communication between healthcare providers and people with cancer.

\section{Acknowledgements}

Conflict of Interest: The authors have no financial conflicts of interest to declare

This project (Academic-Community-Clinical Engagement for Support and Successful outcomes-ACCESS) was supported by grants from the National Center for Research Resources-NCRR (5P20RR016472-12) and the National Institute of General Medical Sciences-NIGMS (8 P20 GM 103446-12) from the National Institutes of Health. 9/3/09-9/2/12.

The funding source had no involvement in the study design, data collection, analysis, writing, or submission of this manuscript for publication.

\section{References}

[1] American Cancer Society (2014) Treatment and Survivorship Research. http://www.cancer.org/research/survivaltreatmentresearch/index

[2] American Cancer Society (2013) Cancer Facts \& Figures 2013. American Cancer Society, Atlanta.

[3] Eheman, C., Berkowitz, Z., Lee, J., Mohile, S., Purnell, J., Rodriguez, E.M., et al. (2009) Information-Seeking Styles among Cancer Patients before and after Treatment by Demographics and Use of Information Sources. Journal of Health Communication: International Perspectives, 14, 487-502. http://dx.doi.org/10.1080/10810730903032945

[4] Walsh, M., Trentham-Dietz, A., Schroepfer, T.A., Reding, D.J., Campbell, B., Foote, M.L., et al. (2010) Cancer Information Sources Used by Patients to Inform and Influence Treatment Decisions. Journal of Health Communication: International Perspectives, 15, 445-463. http://dx.doi.org/10.1080/10810731003753109

[5] Adler, N. and Page, A. (2008) Cancer Care for the Whole Patient: Meeting Psychosocial Health Needs. The National Academies Press, Washington DC.

[6] Hawkins, N., Pollack, L.A., Leadbetter, S., Steele, W.R., Carroll, J., Dolan, J.G., et al. (2008) Informational Needs of Patients and Perceived Adequacy of Information Available before and after Treatment of Cancer. Journal of Psychosocial Oncology, 26, 1-16. http://dx.doi.org/10.1300/J077v26n02 01

[7] Puts, M., et al. (2012) A Systematic Review of Unmet Needs of Newly Diagnosed Older Cancer Patients Undergoing Active Cancer Treatment. Supportive Care in Cancer, 20, 1377-1394.

[8] Posma, E., van Weert, J.C.M., Jansen, J. and Bensing, J.M. (2009) Older Cancer Patients’ Information and Support Needs Surrounding Treatment: An Evaluation through the Eyes of Patients, Relatives, and Professionals. BMC Nursing, 8, 1. http://dx.doi.org/10.1186/1472-6955-8-1

[9] (2007) Cancer Care for the Whole Patient: Meeting Psychosocial Health Needs. http://www.iom.edu/Reports/2007/Cancer-Care-for-the-Whole-Patient-Meeting-Psychosocial-Health-Needs.aspx

[10] (2013) NCCN Guidelines. http://www.nccn.org/professionals/physician_gls/f_guidelines.asp

[11] (2013) Cancer Program Standards 2012, Version 1.2: Ensuring Patient-Centered Care. http://www.facs.org/cancer/coc/programstandards2012.html

[12] Marcusen, C. (2010) Information and Communication Needs of Individuals Living with Advanced Cancer. Seminars in Oncology Nursing, 26, 151-156. http://dx.doi.org/10.1016/j.soncn.2010.05.006

[13] Im, E.O., Chee, W., Guevara, E., Lim, H.J., Liu, Y. and Shin, H. (2008) Gender and Ethnic Differences in Cancer Patients' Needs for Help: An Internet Survey. International Journal of Nursing Studies, 45, 1192-1204. http://dx.doi.org/10.1016/j.ijnurstu.2007.09.006

[14] Klemm, P. (2008) Late Effects of Treatment for Long-Term Cancer Survivors: Qualitative Analysis of an Online Support Group. CIN: Computers, Informatics, Nursing, 26, 49-58. 
http://dx.doi.org/10.1097/01.NCN.0000304753.41493.f4

[15] Fox, S. and Purcell, K. (2010) Chronic Disease and the Internet. http://www.pewinternet.org/2010/03/24/chronic-disease-and-the-internet/

[16] Amalraj, S., Starkweather, C., Nguyen, C. and Naeim, A. (2009) Health Literacy, Communication, and Treatment Decision-Making in Older Cancer Patients. Oncology, 23, 369-375.

[17] Paul, C., Carey, M.L., Hall, A.E., Lynagh, M.C., Sanson-Fisher, R.W. and Henskens, F.A. (2011) Improving Access to Information and Support for Patients with Less Common Cancers: Hematologic Cancer Patients' Views about WebBased Approaches. Journal of Medical Internet Research, 13, e112. http://dx.doi.org/10.2196/jmir.1894

[18] Jefford, M., Black, C., Grogan, S., Yeoman, G., White, V. and Akkerman, D. (2005) Information and Support Needs of Callers to the Cancer Helpline, the Cancer Council Victoria. European Journal of Cancer Care, 14, 113-123. http://dx.doi.org/10.1111/j.1365-2354.2005.00505.x

[19] Carlsson, M. (2009) Cancer Patients Seeking Information from Sources Outside the Health Care System: Change over a Decade. European Journal of Oncology Nursing, 13, 304-305. http://dx.doi.org/10.1016/j.ejon.2009.03.005

[20] Mayer, D., Terrin, N.C., Kreps, G.L., Menon, U., McCance, K., Parsons, S.K., et al. (2007) Cancer Survivors Information Seeking Behaviors: A Comparison of Survivors Who Do and Do Not Seek Information about Cancer. Patient Education and Counseling, 65, 342-350. http://dx.doi.org/10.1016/j.pec.2006.08.015

[21] Reid, J. and Porter, S. (2011) Utility, Caller, and Patient Profile of a Novel Chemotherapy Telephone Helpline Service within a Regional Cancer Centre in Northern Ireland. Cancer Nursing, 34, E27-E32. http://dx.doi.org/10.1097/NCC.0b013e318204c53c

[22] Carlsson, M., Strang, P. and Lindblad, L. (1996) Telephone Help Line for Cancer Counceling and Cancer Information. Cancer Practice, 4, 319-323.

[23] Marcus, A., Garrett, K.M., Kulchak-Rahm, A., Barnes, D., Dortch, W. and Juno, S. (2002) Telephone Counseling in Psychosocial Oncology: A Report from the Cancer Information and Counseling Line. Patient Education \& Counseling, 46, 267-275. http://dx.doi.org/10.1016/S0738-3991(01)00163-X

[24] Rainey, L. (1985) Cancer Counseling by Telephone Help-Line: The UCLA Psychosocial Cancer Counseling Line. Public Health Reports, 100, 308-315.

[25] Morra, M.E., Vevel, J., Nealon, E.O., Mazan, K.D. and Thomsen, C. (1993) History of the Cancer Information Service. Journal of the National Cancer Institute, 7-33.

[26] Carlsson, M. (2000) Cancer Patients Seeking Information from Sources Outside the Health Care System. Supportive Care in Cancer, 8, 453-457.

[27] NCI’s Cancer Information Service (CIS) (2012) http://www.cancer.gov/aboutnci/cis/page1

[28] Bernard, D., Farr, S. and Fang, Z. (2011) National Estimates of Out-of-Pocket Health Care Expenditure Burdens among Nonelderly Adults with Cancer: 2001 to 2008. Journal of Clinical Oncology, 29, 2821-2826. http://dx.doi.org/10.1200/JCO.2010.33.0522

[29] Cunningham, P. (2009) Chronic Burdens: The Persistently High Out-of-Pocket Healthcare Expenses Faced by Many Americans with Chronic Conditions.

http://www.commonwealthfund.org/ /media/Files/Publications/Issue\%20Brief/2009/Jul/Chronic\%20Burdens/1303_C unningham chronic burdens high OOP expenses chronic conditions ib.pdf

[30] Desmond, K., et al. (2007) The Burden of Out-of-Pocket Health Spending among Older versus Younger Adults: Analysis from the Consumer Analysis Survey, 1998-2003. The Henry J. Kaiser Family Foundation.

[31] Finkelstein, E., et al. (2009) The Personal Financial Burden of Cancer for the Working-Aged Population. American Journal of Managed Care, 15, 801-806.

[32] Jayadevappa, R., Schwartz, J.S., Chhatre, S., Gallo, J.J., Wein, A.J. and Malkowicz, S.B. (2010) The Burden of Out-ofPocket and Indirect Costs of Prostate Cancer. The Prostate, 70, 1255-1264. http://dx.doi.org/10.1002/pros.21161

[33] Pisu, M., Azuero, A., McNees, P., Burkhardt, J., Benz, R. and Meneses, K. (2010) The Out of Pocket Cost of Breast Cancer Survivors: A Review. Journal of Cancer Survivorship, 4, 202-209. http://dx.doi.org/10.1007/s11764-010-0125-y

[34] Yabroff, K., Lund, J., Kepka, D. and Mariotto, A. (2011) Economic Burden of Cancer in the United States: Estimates, Projections, and Future Research. Cancer Epidemiology Biomarkers \& Prevention, 20, 2006-2014. http://dx.doi.org/10.1158/1055-9965.EPI-11-0650

[35] Mathews, M. and Park, A. (2009) Identifying Patients in Financial Need: Cancer Care Providers’ Perceptions of Barriers. Clinical Journal of Oncology Nursing, 13, 501-505. http://dx.doi.org/10.1188/09.CJON.501-505

[36] Yabroff, K., Lamont, E.B., Mariotto, A., Warren, J.L., Topor, M., Meekins, A., et al. (2008) Cost of Care for Elderly Cancer Patients in the United States. Journal of the National Cancer Institute, 100, 630-641. 
http://dx.doi.org/10.1093/jnci/djn103

[37] Salz, R., Oeffinger, K.C., McCabe, M.S., Layne, T.M., and Bach, P.B. (2012) Survivorship Care Plans in Research and Practice. CA: A Cancer Journal for Clinicians, 62, 101-117. http://dx.doi.org/10.3322/caac.20142

[38] Hewitt, M., Greenfield, S. and Stovall, E. (2005) From Cancer Patient to Cancer Survivor: Lost in Transition. Institute of Medicine and National Research Council of the National Academies, Washington DC.

[39] (2008) GACHA Annual Report 2008: Delaware Governor’s Advisory Council on Hispanic Affairs. Delaware Health and Social Services, New Castle.

[40] Ennis, S., Rios-Vargas, M. and Albert, N. (2011) The Hispanic Population: 2010. US Census Bureau.

[41] (2012) Cancer Facts and Figures for Latinos/Hispanics 2012-2014. American Cancer Society, Atlanta.

[42] Waters, E., Sullivan, H. and Rutten, L.F. (2009) Cancer Prevention Information-Seeking among Hispanic and NonHispanic Users of the National Cancer Institute's Cancer Information Service: Trends in Telephone and Live-Help Use. Journal of Health Communication: International Perspectives, 14, 476-486. http://dx.doi.org/10.1080/10810730903032952

[43] McCormack, L., et al. (2013) Communication and Dissemination Strategies to Facilitate the Use of Health-Related Evidence. Evidence Report/Technology Assessment No. 213, Rockville. 
Scientific Research Publishing (SCIRP) is one of the largest Open Access journal publishers. It is currently publishing more than 200 open access, online, peer-reviewed journals covering a wide range of academic disciplines. SCIRP serves the worldwide academic communities and contributes to the progress and application of science with its publication.

Other selected journals from SCIRP are listed as below. Submit your manuscript to us via either submit@scirp.org or Online Submission Portal.
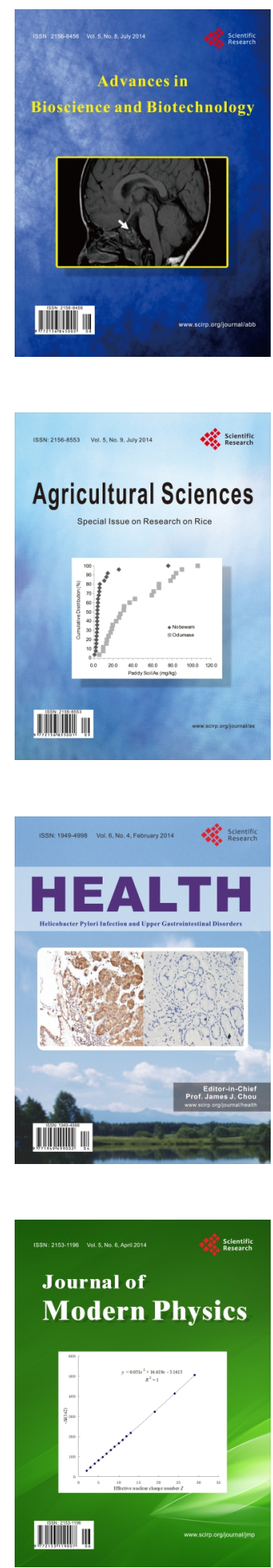
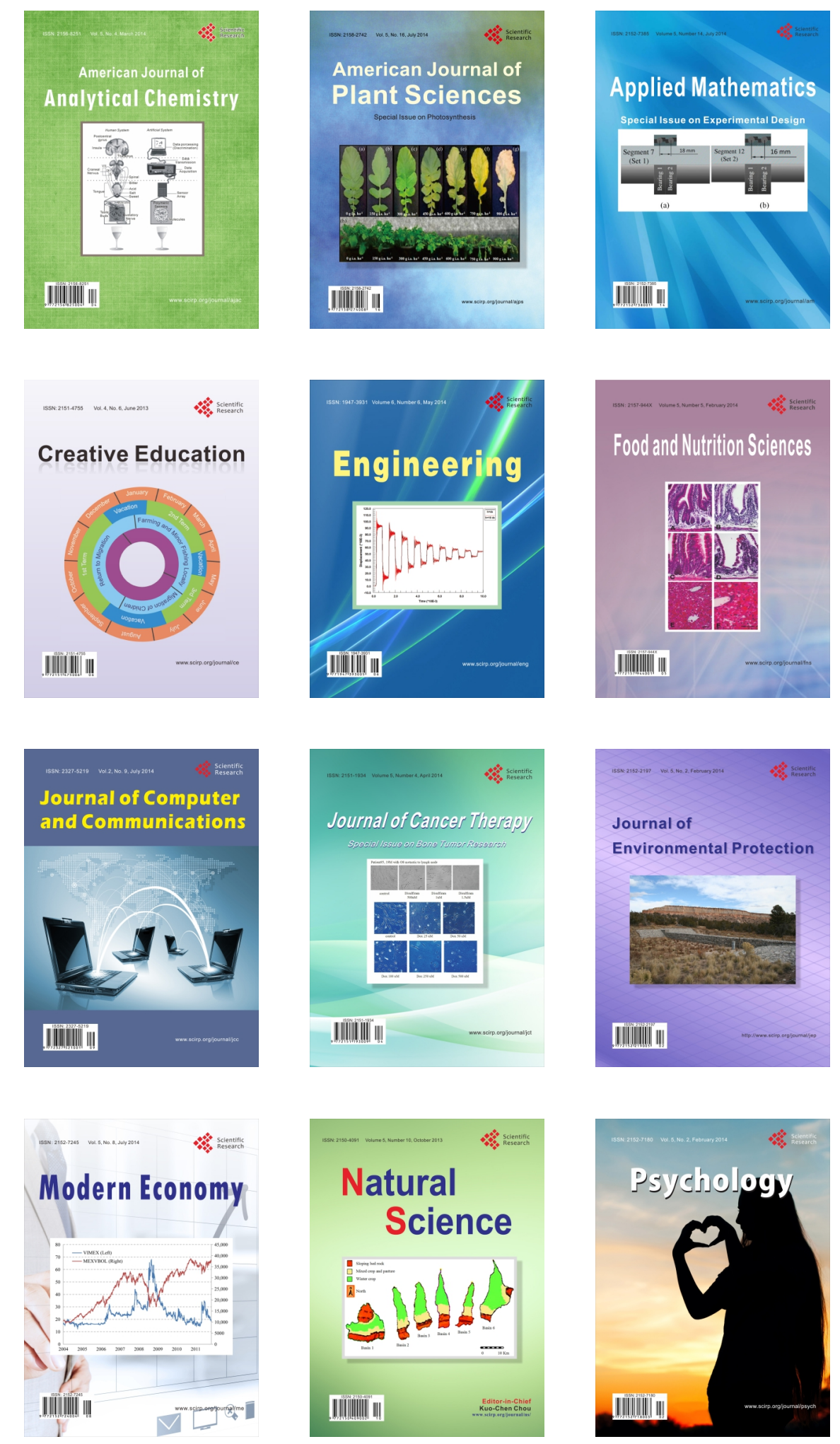